\title{
Durum Wheat Whole-meal Spaghetti with Tomato Peels: How By-product Particles Size Can Affect Final Quality of Pasta
}

\author{
Padalino $L^{1}$, Conte $A^{1}$, Lecce $L^{1}$, Likyova $D^{1}$, Sicari ${ }^{2}$, Pellicanò $T^{2}{ }^{2}$, Poiana $M^{2}$ and Del Nobile MA $^{1 *}$ \\ ${ }^{1}$ University of Foggia, Services Center of Applied Research - Via Napoli 25 Foggia, Italy \\ ${ }^{2}$ Mediterranean University of Reggio Calabria, Agricultural Department, Reggio Calabria, Italy
}

\begin{abstract}
The goal of the study is to investigate the impact of the incorporation of by-product (tomato peels) on durum wheat whole-meal spaghetti. To the aim, different amounts of tomato peels flour were added to pasta dough until the overall sensory quality reached its threshold (peels flour at 15\% TP). Moreover, the effect of different particle sizes of tomato peels addition on sensory quality of pasta was also evaluated. The increase of particle sizes determined a decline of pasta sensory quality. So, samples enriched with fine particles showed high sensory quality, a more acceptable cooking quality and the lowest value of starch digestibility. The utilization of fine particles of tomato peels seems to be useful to enhance the spaghetti quality. Therefore, fine particles allowed obtained fortified pasta with acceptable sensory properties.
\end{abstract}

Keywords: Whole-meal flour; Spaghetti; By-product; Particle sizes; Sensory properties

\section{Introduction}

Over the last decades consumer food demands changed considerably. For this reason, foods today are not intended only to satisfy hunger and to provide necessary nutrients, but also to prevent nutrition-related diseases and enhance physical and mental well-being of consumers $[1,2]$. In this regard, functional foods offer an outstanding opportunity to improve the quality of products. Pasta, in particular, is an important basic food widely consumed across the world and was among the first food to be authorized by the FDA (Food and Drug Administration) as a good vehicle for the addition of bioactive compounds, such as antioxidant compounds and dietary fibre $[3,4]$. However, pasta enriched with bioactive compounds of vegetable origin is still very limited $[5,6]$. Padalino [7] carried out studies to improve nutritional properties of pasta by adding artichoke, asparagus, pumpkin, zucchini, tomato, carrot, broccoli, spinach, eggplant and fennel, all very rich in phenolics and carotenoids that can impart health benefits being able to scavenge reactive oxygen species and protect against degenerative diseases like cancer and cardiovascular diseases.

Tomatoes (Lycopersicon esculentum L.) are known as an excellent source of many nutrients and secondary metabolities, as minerals, vitamins $\mathrm{C}$ and $\mathrm{E}, \beta$-carotene, lycopene, flavonoids, organic acids, phenolics and chlorophyll [8] especially in the peels. Al-Wandawi [9] reported that tomato peels contain high levels of lycopene and $\beta$-carotene compared to pulp and seeds. When tomatoes are processed into products like Catsup, salsa and sauces, $10-30 \%$ of their weight becomes waste or pomace [10]. In fruit and vegetable industry, generally processing leads to one third of the product to be discarded. This can be costly for the manufacturer and also may have a negative impact on the environment. Many researches have shown that byproducts generally exert high nutritional value, could be used as food ingredients, gelling and water binding agents and could provide a valid solution for pollution problems connected with food processing [11]. To the best of our knowledge, no reports are available on the use of tomato peels-based flour in pasta processing. Hence, the aim of this work was to study the impact of tomato peels addition on chemical composition, cooking and sensory quality of whole-meal durum wheat spaghetti. Specifically, the study was organized in the following steps. In the first one, the tomato peels flour amount added to the dough was continuously increased until reaching the sensory threshold (15\% of flour addition). The next experimental step was aimed to investigate the influence of peels particles size on texture properties, cooking quality, sensory and nutritional characteristics of final enriched pasta.

\section{Material and Methods}

\section{Raw materials}

Durum wheat seeds Pr22 were provided from the C.R.A. (Foggia, Italy). The whole-meal flour was produced from grinding of the seeds with a stone mill (Mod MB250 Partisani). Tomato skins of different cultivars (Ulisse, Docet, Ercole, Player, Herdon, Fuzzer and Komolix), obtained in the crop year 2012-2013 in Campania and Apulia (Southern Italy) industries, were used. Tomato skins were dehydrated by exposure to sunlight and then in the oven $\left(40-50^{\circ} \mathrm{C}\right)$ and the flour was produced by hammer mill (16/BV-Beccaria s.r.l. Cuneo).

After the flour was sieved by Sieve Shakers (Mod AS 300 Retsch) in different particles sizes: fine particles size (FPS $-\geq 63 \mu \mathrm{m}$ ), medium particles size (MPS - $\geq 125 \mu \mathrm{m}$ ) and coarse particles size (CPZ - $\geq 250 \mu \mathrm{m}$ ).

\section{Spaghetti preparation}

Whole-meal flour of durum wheat was mixed with water $(30 \%$ $\mathrm{w} / \mathrm{w}$ ) in the rotary shaft mixer (Namad, Rome, Italy) at $25^{\circ} \mathrm{C}$ for 20 minutes to uniformly distribute water. In the first experimental phase, the tomato peels flour (particles size $<500 \mu \mathrm{m}$ ) was added to the wheat flour at various concentrations: $10 \%, 15 \%, 20 \%$ and $25 \%(\mathrm{w} / \mathrm{w})$. In a subsequent experimental phase the sample with $15 \%$ addition (15-TP) was prepared by tomato peels flour to different particle sizes: $63 \mu \mathrm{m}(15-$ TP/FPS), $125 \mu \mathrm{m}$ (15-TP/MPS) and $250 \mu \mathrm{m}$ (15-TP/CPS). Spaghetti

*Corresonding author: Matteo Alessandro Del Nobile, University of Foggia Services Center of Applied Research - Via Napoli 25 Foggia, Italy, Tel: + 390881589242; E-mail: matteo.delnobile@unifg.it

Received August 20, 2015; Accepted September 07, 2015; Published September 11, 2015

Citation: Padalino L, Conte A, Lecce L, Likyova D, Sicari V, et al. (2015) Durum Wheat Whole-meal Spaghetti with Tomato Peels: How By-product Particles Size Can Affect Final Quality of Pasta. J Food Process Technol 6: 500. doi:10.4172/2157. 7110.1000500

Copyright: (c) 2015 Padalino L, et al. This is an open-access article distributed under the terms of the Creative Commons Attribution License, which permits unrestricted use, distribution, and reproduction in any medium, provided the original author and source are credited. 
based only on whole-meal flour were also manufactured and used as the reference sample (CTRL). In all the steps, dough was extruded with a 60VR extruder (Namad). Subsequently, the pasta was dried in a dryer (SG600; Namad). The process conditions were in according Padalino [12].

\section{Sensory analysis}

Dry spaghetti samples were submitted to a panel of fifteen trained tasters (six men and nine women, aged between 28 and 45) in order to evaluate the sensory attributes. The panelists were also trained in sensory vocabulary and identification of particular attributes by evaluating durum wheat commercial spaghetti [13]. They were asked to indicate color and resistance to break of uncooked spaghetti. Elasticity, firmness, bulkiness, adhesiveness, fibrous nature, color, odor and taste were evaluated for cooked spaghetti. To this aim, a nine-point scale, where one corresponded to extremely unpleasant, nine to extremely pleasant and five to the threshold acceptability, was used to quantify each attribute [14]. On the basis of the above-mentioned attributes, panelists were also asked to score the overall quality of the product using the same scale.

\section{Chemical determination}

Dry spaghetti samples were ground to fine flour on a Tecator Cyclotec 1093 (International PBI, Hoganas, Sweden) laboratory mill (1mm screen - 60 mesh). Moisture and ash content (\%) were measured according to AACC method [15]. Protein content $(\% \mathrm{~N} \times 5.7)$ was analyzed using the micro-Kjeldahl method according to AACC method [15]. Total dietary fiber (TDF), soluble water dietary fiber (SDF) and insoluble water dietary fiber (IDF) contents were determined by means of the total dietary fiber kit (Megazyme International Ireland Ltd., Wicklow, Ireland) based on the method of Lee [16]. The available carbohydrates $(\mathrm{ACH})$ were determined according to the method of McCleary [17] as described in the ACH assay kit (Megazyme). All nutritional analyses of the flour and spaghetti samples were made in triplicate.

For the carotenoids determination spaghetti were homogenized in a blender and an aliquot of $10 \mathrm{~g}$ was added of $100 \mathrm{ml}$ of solvent mix (esano:acetone:methanol; 2:1:1; v/v/v) and sonication continuously for 10 min (Misonix Ultrasonic Liquid Processor, NY, U.S.A). The extraction was repeated until sample became colorless. The combined extract was transferred to a separating funnel and $5 \mathrm{ml}$ of distilled water was added to separate polar and nonpolar phases. The nonpolar hexane layer containing carotenoids was collected and concentrated in a rotary evaporator (Heidolph, Germany) till dryness. Residue was dissolved in $10 \mathrm{ml}$ of hexane. Lycopene and $\beta$-carotene were determined according to Fish [18] by a spectrophotometric method using an Agilent 8453 UV-Vis spectrophotometer. The concentration of lycopene was calculated at $\lambda=503 \mathrm{~nm}$ using the molar extinction coefficient $\beta=17.2$ $\times 10^{4} / \mathrm{M} / \mathrm{cm}$. For $\beta$-carotene, the absorbance was measured at $\lambda=450$ $\mathrm{nm}$ and the quantification were carried out using a standard curve. All the nutritional analyses were made in triplicate and the results were expressed as mean \pm standard deviation (SD).

\section{Cooking quality}

The optimal cooking time (OCT) was evaluated in according to the AACC approved method [15]. The cooking loss, the amount of solid substance lost to cooking water, was determined according to the AACC approved method 66-50. The swelling index and the water absorption of the cooked pasta (grams of water per gram of dry pasta) were determined according to the procedure described by Padalino [12].
Moreover, the cooked spaghetti samples to OCT were submitted to hardness and adhesiveness analysis, by means of a Zwick/Roell model Z010 Texture Analyzer (Zwick Roell Italia S.r.l., Genova, Italia) equipped with a stainless steel cylinder probe $(2 \mathrm{~cm}$ diameter). The hardness (mean maximum force, $\mathrm{N}$ ) and adhesiveness (mean negative area, $\mathrm{Nmm}$ ) were measured in according to the procedure described by Padalino [12]. Six measurements for each spaghetti sample were performed.

\section{In vitro digestion}

The digestion was carried out as described by Chillo [19] with slight modifications. Briefly, dry spaghetti samples $(5 \mathrm{~g})$ were broken into $5.0 \times 1.0 \mathrm{~cm}$ lengths and weighed accurately. Fifty milliliters of boiling water was immediately placed in a covered boiling water bath to cook the spaghetti to the OCT. The spaghetti were tipped into a digestion vessel with $50 \mathrm{ml}$ of distilled water and $5 \mathrm{ml}$ maleate buffer $\left(0.2 \mathrm{M} \mathrm{pH} 6.0\right.$, containing $0.15 \mathrm{~g} \mathrm{CaCl}_{2}$ and $0.1 \mathrm{~g}$ sodium azide per liter) in an block at $37^{\circ} \mathrm{C}$ (GFL 1092; GFL Gesellschaft für Labortechnik, Burgwedel, Germany) and allowed to equilibrate for $15 \mathrm{~min}$. Digestion was started by adding $0.1 \mathrm{ml}$ amyloglucosidase (A 7095; Sigma Aldrich, Milan, Italy) and $1 \mathrm{ml}$ of $2 \mathrm{~g}$ per $100 \mathrm{~g}$ pancreatin (P7545; Sigma Aldrich) in quick succession and the vessels were stirred at $130 \mathrm{rpm}$. An amount of $0.5 \mathrm{ml}$ of the digested samples was taken at $0,20,60$ and $120 \mathrm{~min}$ for the released glucose analysis. The sample digested to $120 \mathrm{~min}$ was homogenized through an Ultra Turrax (Ika Werke, Staufen, Germany).

\section{Analysis of digested starch}

The samples removed during digestion were added to $2.0 \mathrm{ml}$ of ethanol ethanol and mixed. After $1 \mathrm{~h}$, the ethanolic sub-samples were centrifuged (2000 g, 2 min) (Biofuge fresco; Heraeus, Hanau, Germany). Finally, the reducing sugar concentration was measured colorimetrically $(\mathrm{k}=530 \mathrm{~nm})$ using a Shimadzu UV-Vis spectrophotometer (model 1700; Shimadzu corporation, Kyoto, Japan). Glucose standards of 10 $\mathrm{mg} / \mathrm{ml}$ were used. Amyloglucosidase $(0.25 \mathrm{ml})$ (EAMGDF, $1 \mathrm{ml}$ per 100 $\mathrm{ml}$ in sodium acetate buffer $0.1 \mathrm{M}, \mathrm{pH}$ 5.2; Megazyme International 205 Ireland Ltd., Wicklow, Ireland) was added to $0.05 \mathrm{ml}$ of the supernatant and incubated at $20^{\circ} \mathrm{C}$ for $10 \mathrm{~min}$. Afterwards, $0.75 \mathrm{ml}$ DNS solution (10\% 3,5-dinitrosalicylic acid, $16 \% \mathrm{NaOH}$ and $30 \% \mathrm{Na}-\mathrm{K}$ tartrate Sigma Aldrich) was added to the above solution, heated to $100^{\circ} \mathrm{C}$ for $15 \mathrm{~min}$ and allowed to cool at $15^{\circ} \mathrm{C}$ for $1 \mathrm{~h}$. Then, $4 \mathrm{ml}$ of distilled water $\left(15^{\circ} \mathrm{C}\right)$ were added to the solution. The results were plotted as glucose release $(\mathrm{mg})$ per $\mathrm{g}$ of sample vs. time. The starch digestibility was calculated as the area under the curve $(0-120 \mathrm{~min})$ for the tested products, and expressed as the percentage of the corresponding area for white bread [19].

\section{Statistical analysis}

Experimental data were compared by a one-way variance analysis (ANOVA). A Duncan's multiple range test, with the option of homogeneous groups $(\mathrm{P}<0.05)$, was carried out to determine significant differences between spaghetti samples. STATISTICA 7.1 for Windows (StatSoft, Inc, Tulsa, OK, USA) was used for this aim.

\section{Results and Discussion}

As reported above, the experimental plan has been organized in two subsequent steps, the first aimed to find the better concentration of tomato peels amount to be added to the dough and the second one, to study the effects of peel-particles size on quality of spaghetti. Results of each step were detailed in different paragraphs. 


\section{Step 1 - Optimization of tomato peels flour addition}

The sensory properties of dry spaghetti samples are listed in Table 1. Results highlighted that in general the overall quality of spaghetti made with whole-meal flour (CTRL) without any peels addition was higher in comparison to the samples supplemented with tomato peels flour, above all at concentrations higher than $15 \%$. In particular, in the uncooked spaghetti poor colour and break to resistance were found. Regarding the cooked spaghetti, the addition of tomato peels flour influenced pasta elasticity and firmness, due to the high fibres content. Incorporation of vegetable matter rendered a firmer texture to pasta sample due to the nonstarchy nature of vegetables. In addition, the TDF content of tomato peels (mainly insoluble fibers) was found higher than that reported in other vegetables [20]. Similar results were observed by Yavad et al. [6], who found an increase of pasta firmness (100\% durum wheat) enriched with vegetable flour. The low elasticity value was also due to the inclusion of tomato peels fibres that promoted the formation of discontinuities or cracks inside the pasta strand, which weakened its structure. Spaghetti fortified with tomato peels flour resulted less adhesive than the CTRL sample, even if the differences between samples were not significant. Stickiness did not increase in the different pasta samples, most probably because fibres addition is generally recognized to have a positive effect on stickiness [21]. Spaghetti exclusively made with whole-meal wheat or containing amounts of tomato peels flour up to $15 \%(\mathrm{w} / \mathrm{w})$ appeared with a pleasant brown colour, whereas, the spaghetti samples made by using more than $15 \%$ tomato peels flour present an intense orange colour, which is different from the common pasta and considered unacceptable. Rekna [5] also observed reduction in colour intensity of cooked pasta enriched with vegetable flour, probably due to the pasta swelling and to the conversion of pigments resulting in a yellowness increase. Colour is the key factor for assessing the visual quality and market value of food products [22]. Svec [23] also studied the colour impact of non-traditional cereals and reported that until $10 \%$ addition the colour remained acceptable. In addition, spaghetti samples enriched with tomato peels flour had very intense taste and odour as compared to the CTRL sample. Therefore, on the basis of the sensory acceptability, the spaghetti samples enriched with tomato peels flour at $15 \%$ were selected for the subsequent work of pasta optimization.

\section{Step 2 Effects of tomato peels particles size on spaghett quality}

Sensory analysis: The results of sensory properties of dry spaghetti are listed in Table 2. As can be inferred, the overall quality of uncooked and cooked spaghetti declined as the particles size increased, thus demonstrating that spaghetti enriched with the fine particles (15TP/FPS) exerted the greatest overall quality. In terms of firmness no differences among samples were recorded, even though a little increase was found in pasta with fine particles because these particles contain more protein than coarse particles of tomato peels. Padalino [12] also found that the high protein content of pea flour increased pasta hardness due to low hydration of starch granules. Most probably, during cooking, the protein can link to most of the water molecules, leaving less water to swell the starch phase [24]. From data reported in Table 2 it is also clear that particles size has a marked effect on the fibrous nature of spaghetti. As compared to the other samples, the 15-TP/FPS showed a low fibrous sensation, due to the less dietary fibres content (Table 3), and present low adhesiveness and bulkiness. One possible explanation of the observed results is that with fine particles a more stable network can be realized, able to bind starch granules and vegetable flour and avoid solids loss during cooking [5]. No effects of particles size were underlined on pasta odour. Samples 15-TP/FPS and 15-TP/MPS in particular showed a pleasant orange colour. As concern the taste, the most prized samples were again 15-TP/FPS and 15-TP/MPS, due to the low fibrous sensation during mastication.

Chemical composition: Table 3 summarizes the protein and the dietary fibres content of spaghetti. It is clear that particles size of peels had no effects on protein and available carbohydrates content. A certain drop in dietary fibres for samples supplemented with fine particles (12.69\%), in comparison to medium and coarse sizes $(14.78 \%)$ was observed. It is plausible to suggest that the use of flour with coarse particles better corresponds to more functional compounds, such as dietary fibres [25]. Table 3 also reports the results of the in vitro starch digestibility. Results suggested that the particles size influenced the starch digestibility (SD). It can be seen a significant decline of SD in spaghetti enriched with coarse particles size. These differences could be due to the fact that the sample 15-TP/CSP had the greatest dietary fibres content that are known to reduce the glycaemic response of pasta [26]. These results also are also in agreement with Padalino [7], who

\begin{tabular}{|c|c|c|c|c|c|c|c|c|c|c|c|c|}
\hline & \multicolumn{3}{|c|}{ Uncooked Spaghetti } & \multicolumn{9}{|c|}{ Cooked Spaghetti } \\
\hline & Color & $\begin{array}{l}\text { Break to } \\
\text { Resistance }\end{array}$ & $\begin{array}{l}\text { Overall } \\
\text { Quality }\end{array}$ & Elasticity & Firmness & Fibrous & Bulkiness & Adhesiveness & Color & Odor & Taste & $\begin{array}{l}\text { Overall } \\
\text { Quality }\end{array}$ \\
\hline CTRL & $7.26 \pm 0.35^{\mathrm{a}}$ & $6.20 \pm 0.34^{a}$ & $7.09 \pm 0.30^{\mathrm{a}}$ & $7.09 \pm 0.33^{a}$ & $6.83 \pm 0.30^{\mathrm{a}}$ & $6.83 \pm 0.25^{a}$ & $6.37 \pm 0.28^{a}$ & $6.09 \pm 0.28^{a}$ & $7.00 \pm 0.23^{a}$ & $7.31 \pm 0.41^{\mathrm{a}}$ & $7.07 \pm 0.44^{\mathrm{a}}$ & $7.09 \pm 0.33^{a}$ \\
\hline $10 \%$ TP & $6.48 \pm 0.42^{b}$ & $5.91 \pm 0.38^{\mathrm{a}, \mathrm{b}}$ & $6.20 \pm 0.27^{b}$ & $5.57 \pm 0.33^{a}$ & $6.50 \pm 0.31^{a, b}$ & $5.78 \pm 0.26^{b}$ & $6.51 \pm 0.40^{a}$ & $6.02 \pm 0.40^{a}$ & $6.80 \pm 0.33^{a, b}$ & $6.21 \pm 0.40^{\mathrm{b}}$ & $6.26 \pm 0.34^{b}$ & $6.30 \pm 0.34^{b}$ \\
\hline $15 \%$ TP & $6.08 \pm 0.20^{\mathrm{a}, \mathrm{b}}$ & $5.80 \pm 0.24^{\mathrm{a}, \mathrm{b}}$ & $6.05 \pm 0.25^{\mathrm{a}, \mathrm{b}}$ & $5.37 \pm 0.31^{a}$ & $6.31 \pm 0.23^{a, b}$ & $5.68 \pm 0.28^{b}$ & $6.60 \pm 0.39^{a}$ & $6.11 \pm 0.40^{\mathrm{a}}$ & $6.30 \pm 0.36^{\mathrm{b}, \mathrm{c}}$ & $6.01 \pm 0.21^{\mathrm{b}}$ & $6.11 \pm 0.28^{b}$ & $6.04 \pm 0.38^{b, c}$ \\
\hline $20 \%$ TP & $5.65 \pm 0.36^{\mathrm{c}, \mathrm{d}}$ & $5.65 \pm 0.27^{\mathrm{a}, \mathrm{b}}$ & $5.62 \pm 0.31^{\mathrm{c}, \mathrm{d}}$ & $5.17 \pm 0.36^{\mathrm{a}}$ & $6.01 \pm 0.34^{b}$ & $5.28 \pm 0.28^{b, c}$ & $6.65 \pm 0.34^{a}$ & $6.17 \pm 0.24^{a}$ & $6.01 \pm 0.23^{c}$ & $5.81 \pm 0.33^{b}$ & $5.91 \pm 0.21^{b}$ & $5.64 \pm 0.37^{b, c}$ \\
\hline $25 \%$ TP & $5.22 \pm 0.27^{d}$ & $5.36 \pm 0.28^{b}$ & $5.33 \pm 0.30^{d}$ & $5.07 \pm 0.36^{a}$ & $5.25 \pm 0.37^{c}$ & $5.01 \pm 0.34^{c}$ & $6.67 \pm 0.33 a$ & $6.24 \pm 0.27 a$ & $5.95 \pm 0.24^{c}$ & $6.20 \pm 0.33^{b}$ & $5.55 \pm 0.40^{b}$ & $5.46 \pm 0.38^{c}$ \\
\hline
\end{tabular}

a-cMean in the same column followed by different superscript letters differ significantly $(P<0.05)$.

Table 1: Sensory characteristics of uncooked and cooked dry spaghetti samples obtained in step 1.

\begin{tabular}{|c|c|c|c|c|c|c|c|c|c|c|c|c|}
\hline & \multicolumn{3}{|c|}{ Uncooked Spaghetti } & \multicolumn{9}{|c|}{ Cooked Spaghetti } \\
\hline & Color & $\begin{array}{l}\text { Break to } \\
\text { Resistance }\end{array}$ & $\begin{array}{l}\text { Overall } \\
\text { Quality }\end{array}$ & Elasticity & Firmness & Fibrous & Bulkiness & Adhesiveness & Color & Odor & Taste & $\begin{array}{l}\text { Overall } \\
\text { Quality }\end{array}$ \\
\hline $15 \% \mathrm{TP}$ & $6.08 \pm 0.20^{b}$ & $5.80 \pm 0.24^{a}$ & $6.05 \pm 0.25^{b}$ & $5.37 \pm 0.31^{\text {a }}$ & $6.31 \pm 0.23^{a}$ & $5.68 \pm 0.28^{\mathrm{a}, \mathrm{b}}$ & $6.60 \pm 0.39^{\mathrm{a}, \mathrm{b}}$ & $6.11 \pm 0.40^{\mathrm{a}, \mathrm{b}}$ & $6.30 \pm 0.36^{b}$ & $6.01 \pm 0.21^{\circ}$ & $6.11 \pm 0.28^{b}$ & $6.04 \pm 0.38^{b}$ \\
\hline $15 \%$ TP/FPS & $7.21 \pm 0.27^{a}$ & $6.32 \pm 0.34^{a}$ & $6.84 \pm 0.32^{a}$ & $6.04 \pm 0.34^{a}$ & $6.35 \pm 0.36^{a}$ & $6.26 \pm 0.34^{\mathrm{a}}$ & $6.85 \pm 0.34^{a}$ & $6.63 \pm 0.35^{\circ}$ & $7.16 \pm 0.32^{\mathrm{a}}$ & $6.04 \pm 0.23^{\circ}$ & $6.81 \pm 0.24^{a}$ & $6.98 \pm 0.27^{a}$ \\
\hline $15 \%$ TP/MPS & $7.18 \pm 0.23^{a}$ & $6.10 \pm 0.31^{a}$ & $6.59 \pm 0.31^{\mathrm{a}, \mathrm{b}}$ & $5.69 \pm 0.40^{\mathrm{a}}$ & $6.20 \pm 0.33^{a}$ & $6.10 \pm 0.28^{a, b}$ & $6.56 \pm 0.40^{\mathrm{a}, \mathrm{b}}$ & $6.02 \pm 0.40^{\mathrm{a}, \mathrm{b}}$ & $7.12 \pm 0.24^{\mathrm{a}}$ & $6.06 \pm 0.23^{\circ}$ & $6.73 \pm 0.22^{a}$ & $6.53 \pm 0.43^{a, b}$ \\
\hline $15 \%$ TP/CMS & $6.09 \pm 0.39^{b}$ & $5.94 \pm 0.35^{a}$ & $6.11 \pm 0.24^{b}$ & $5.64 \pm 0.35^{a}$ & $6.07 \pm 0.26^{a}$ & $5.54 \pm 0.28^{b}$ & $6.00 \pm 0.28^{b}$ & $5.75 \pm 0.31^{b}$ & $6.39 \pm 0.48^{b}$ & $6.08 \pm 0.26^{\circ}$ & $6.09 \pm 0.28^{b}$ & $6.15 \pm 0.30^{b}$ \\
\hline
\end{tabular}

a-cMean in the same column followed by different superscript letters differ significantly $(P<0.05)$

Table 2: Sensory characteristics of uncooked and cooked dry spaghetti samples obtained in step 2. 
also found that the addition of pepper flour (containing a high level of dietary fibres) reduced the glycemic index of maize-based pasta.

Table 4 shows the lycopene and $\beta$-carotene content in spaghetti samples enriched with tomato peels flour. Data were expressed as $\mathrm{mg}$ of $\beta$-carotene and lycopene $/ 100 \mathrm{~g}$ spaghetti. There were differences $(\mathrm{P}<$ $0.05)$ among studied samples, thus highlighting that particles of tomato peels decreased concentration of carotenoids mainly for $\beta$-carotene. As one could expect, the spaghetti 15-TP have the highest value of lycopene $(2.32 \mathrm{mg} / 100 \mathrm{~g})$ and $\beta$-carotene $(13.64 \mathrm{mg} / 100 \mathrm{~g})$ compared to the other ones. It is also worth noting that even with fine particles, a significant increment of carotenoids can be obtained, if compared to the control samples.

Cooking quality: The optimum cooking time, the cooking loss, the swelling index and the water absorption of spaghetti samples are presented in Table 5. From this table emerges that particles size of peels flour also affects cooking quality. In fact, the OCT decreased as the particles size increased. Specifically, the OCT for samples supplemented with fine and medium particles was higher (9.00 and 8.30 min respectively) than $15-\mathrm{TP}$ and $15-\mathrm{TP} / \mathrm{CPS}$ samples, likely due to the protein matrix-starch granule network, which was affected by the vegetable flour fibres. The physical disruption of gluten matrix caused by fibres addition and the reduction in gluten content due to tomato peels flour addition may facilitate the water penetration into pasta core. The less cooking time of pasta supplemented with vegetable flour could be explained by the faster reconstitution of fine vegetable matter distributed in pasta matrix [5]. Table 5 also shows a decline in cooking loss for samples 15-TP/FPS and 15-TP/MPS, as compared to the other pasta samples. As reported for sensory analysis, these results could be mainly due to the better binding of starch granules and vegetable flour with fine particles size in gluten network [5]. Concerning the swelling index, significant differences were observed with the increase of particles size. Specifically, the 15-TP/CPS sample showed the highest swelling index. The 15-TP/CPS presented agreater water absorption than the other samples, but without any significant differences. These results could be explained by the reduction of protein, as resulting from the increment of the average particles size. In fact, the sample with the coarse particles showed a slight drop in protein content that is known to counteract starch granule swelling during cooking, due to competition between protein and starch for water availability [24]. Regarding the adhesiveness, the 15-TP/FPS sample recorded the smallest value $(0.51 \mathrm{~N})$, and concerning the hardness, the same sample recorded the highest value, in accordance to sensory quality and cooking loss. This result also suggests that the high protein content of sample with fine particles of peels increased the hardness of pasta because of the low hydration of starch granules.

\section{Conclusions}

In this work, the impact of tomato peels-based flour addition on chemical composition, cooking and sensory quality of whole-meal durum wheat spaghetti was studied. In the first experimental step, tomato peels flour amount added to pasta dough was continuously increased until the sensory quality reached the threshold (tomato peels flour concentration 15\%). In a second step, the influence of particles size on sensory quality of pasta with $15 \%$ tomato peels flour was investigated. The results indicated that the increase of particles size determined a decline of overall quality of samples; even a slight better nutritional composition was recorded. Specifically, the spaghetti enriched with the fine particles showed the greatest sensory score, due to the low fibrous, low adhesiveness, low bulkiness and high hardness values and showed a significant increase of starch digestibility. Therefore, our findings suggest that whole-meal spaghetti with fine particles represent fortified pasta with good sensory properties, very comparable to the control samples, and good cooking quality. This example of pasta fortification can offer a broad spectrum of new products with desired properties and encourage the use of agronomic by-products for further studies and new food applications.

\begin{tabular}{|c|c|c|c|c|c|c|}
\hline Sample & Protein (\%) & ACH (g/100g) & IDF (\%) & SDF (\%) & TDF (\%) & SD \\
\hline $15 \%$ TP & $10.29 \pm 0.18^{\mathrm{a}, \mathrm{b}}$ & $59.10 \pm 0.10^{\mathrm{a}, \mathrm{b}}$ & $14.95 \pm 0.00^{\mathrm{a}}$ & $8.00 \pm 0.28^{\mathrm{a}}$ & $22.95 \pm 0.14^{\mathrm{a}}$ & $58 \pm 0.30^{\mathrm{b}}$ \\
\hline $\mathbf{1 5 \%}$ TP/FPS & $10.35 \pm 0.30^{\mathrm{a}}$ & $58.03 \pm 0.90^{\mathrm{b}}$ & $12.69 \pm 0.01^{\mathrm{d}}$ & $7.06 \pm 0.00^{\mathrm{c}}$ & $19.75 \pm 0.00^{\mathrm{d}}$ & $62 \pm 0.90^{\mathrm{a}}$ \\
\hline $\mathbf{1 5 \%}$ TP/MSP & $10.20 \pm 0.06^{\mathrm{a}, \mathrm{b}}$ & $60.20 \pm 0.00^{\mathrm{a}}$ & $13.01 \pm 0.61^{\mathrm{c}}$ & $7.42 \pm 0.00^{\mathrm{b}}$ & $20.48 \pm 0.00^{\mathrm{c}}$ & $61 \pm 1.00^{\mathrm{a}}$ \\
\hline $\mathbf{1 5 \%}$ TP/CSP & $9.95 \pm 0.05^{\mathrm{b}}$ & $59.02 \pm 1.20^{\mathrm{a}, \mathrm{b}}$ & $14.78 \pm 0.09^{\mathrm{b}}$ & $7.33 \pm 0.20^{\mathrm{b}, \mathrm{c}}$ & $22.11 \pm 0.10^{\mathrm{b}}$ & $53 \pm 0.20^{\mathrm{c}}$ \\
\hline
\end{tabular}

TDF: Total Dietary Fibre; SDF: Soluble Water Dietary Fibre; IDF: Insoluble Water Dietary Fibre; ACH: Available Carbohydrates; SD: Starch Digestibility ${ }^{a-c}$ Mean in the same column followed by different superscript letters differ significantly $(P<0.05)$.

Table 3: Chemical composition of semolina and pea flour and dry spaghetti samples obtained in step 2.

\begin{tabular}{|c|c|c|}
\hline & lycopene & \multicolumn{1}{c|}{$\begin{array}{c}\text {-carotene } \\
\text { (mg/100g spaghetti) }\end{array}$} \\
\cline { 2 - 3 } & (mg/ 100g spaghetti) & $4.23 \pm 0.23^{\mathrm{e}}$ \\
\hline cnt & $0.03 \pm 0.01^{\mathrm{d}}$ & $13.64 \pm 1.15^{\mathrm{a}}$ \\
\hline $\mathbf{1 5 \%}$ TP & $2.32 \pm 0.4^{6} \mathrm{a}$ & $10.46 \pm 0.10^{\mathrm{d}}$ \\
\hline $\mathbf{1 5} \%$ TP/MPS & $1.31 \pm 0.10^{\mathrm{b}}$ & $11.60 \pm 0.91^{\mathrm{b}}$ \\
\hline $\mathbf{1 5} \%$ TP/CSP & $1.00 \pm 0.12^{\mathrm{c}}$ & $10.87 \pm 1.31^{\mathrm{c}}$ \\
\hline
\end{tabular}

${ }^{a-c}$ Mean in the same column followed by different superscript letters differ significantly $(P<0.05)$.

Table 4: Carotenoids content of dry spaghetti obtained in step 2.

\begin{tabular}{|c|c|c|c|c|c|c|}
\hline Sample & OCT (min) & Cooking Loss (\%) & Swelling Index & Water Absorption (\%) & Adhesiveness (Nmm) & Hardness (N) \\
\hline $15 \% \mathrm{TP}$ & 7.30 & $8.47 \pm 0.07^{a}$ & $1.72 \pm 0.10^{\mathrm{b}}$ & $138 \pm 3.65^{a}$ & $0.58 \pm 0.08^{a}$ & $14.60 \pm 1.13^{a}$ \\
\hline $15 \%$ TP/FPS & 9.00 & $6.91 \pm 0.31^{c}$ & $1.71 \pm 0.09^{b}$ & $139 \pm 8.48^{a}$ & $0.41 \pm 0.06^{b}$ & $13.93 \pm 0.67^{\mathrm{a}, \mathrm{b}}$ \\
\hline $15 \%$ TP/MSP & 8.30 & $7.94 \pm 0.40^{\mathrm{b}}$ & $1.70 \pm 0.05^{b}$ & $140 \pm 4.20^{\mathrm{a}}$ & $0.61 \pm 0.09^{a}$ & $13.03 \pm 0.92^{\mathrm{a}, \mathrm{b}}$ \\
\hline $15 \% \mathrm{TP} / \mathrm{CSP}$ & 8.00 & $8.53 \pm 0.14^{\mathrm{a}}$ & $1.86 \pm 0.01^{\mathrm{a}}$ & $144 \pm 4.00^{\mathrm{a}}$ & $0.57 \pm 0.10^{\mathrm{a}}$ & $12.61 \pm 0.81^{b}$ \\
\hline
\end{tabular}

a-c Mean in the same column followed by different superscript letters differ significantly $(P<0.05)$.

Table 5: Cooking quality of spaghetti enriched with tomato peels flours at different particle size studied in step 2 . 
Citation: Padalino L, Conte A, Lecce L, Likyova D, Sicari V, et al. (2015) Durum Wheat Whole-meal Spaghetti with Tomato Peels: How By-product Particles Size Can Affect Final Quality of Pasta. J Food Process Technol 6: 500. doi:10.4172/2157-7110.1000500

\section{References}

1. Betoret E, Betoret N, Vidal D, Fito P (2011) Functional foods development: trends and technologies. Trends Food Sci Tech 22: 498-508.

2. Brouns F, Vermeer C (2000) Functional ingredients for reducing the risks of osteoporosis. Trends Food Sci Tech 11: 22-33.

3. Chillo S, Laverse J, Falcone PM, Protopapa A, Del Nobile MA (2008) Influence of the addition of buckwheat flour and durum wheat bran on spaghetti quality. J Cereal Sci 47: 144-152.

4. Gallegos-Infante JA, Rocha-Guzman NE, Gonzalez-Lared RF, Ochoa-Martínez LA, Corzo N, et al. (2010) Quality of spaghetti pasta containing Mexican common bean flour (Phaseolus vulgaris L.). Food Chem 119: 1544-1549.

5. Rekha MN, Chauhan AS, Prabhasankar P, Ramteke RS, Venkateswara Rao G (2012) Influence of vegetable pastes on quality attributes of pastas made from bread wheat (T. aestivum). CyTA J Food 11: 142-149.

6. Deep NY, Yadav M, Sharma N, Chikara T, Anand SB, et al. (2014) Quality Characteristics of Vegetable-Blended Wheat-Pearl Millet Composite Pasta. Agr Res 3: 263-270.

7. Padalino L, Mastromatteo M, Lecce L, Cozzolino F, Del Nobile MA, et al (2013a) Manufacture and characterization of gluten free spaghetti enriched with vegetable flour. J Cereal Sci 57: 333-342.

8. Giovanelli G, Paradise A (2002) Stability of dried and intermediate moisture tomato pulp during storage. J Agr Food Chem 50: 7277-7281.

9. Al-Wandawi H, Abdul Rehman MH, Al Shaikhly KA (1985) Tomato processing wastes as essential raw materials source. J Agr Food Chem 33: 804-807.

10. King AJ, Zeidler G (2004) Tomato pomace may be a good source of vitamin $E$ in broiler diets. Cal Agr 58: 59-62.

11. Lario Y, Sendra E, Garciá-Pérez J, Fuentes C, Sayas-Barberá E, et al. (2004) Preparation of high dietary fiber powder from lemon juice by-products. Innov Food Sci Emerg Tech 5: 113-117.

12. Padalino L, Mastromatteo M, Lecce L, Spinelli S, Contò F, et al. (2013) Chemical composition, sensory and cooking quality evaluation of durum wheat spaghetti enriched with pea flour. Int J Food Sci Tech 49: 1-13.

13. ISO 11036/7304-2 (2008) Alimentary pasta produced from durum wheat semolina-Estimation of cooking quality by sensory analysis - Part 2: Routine Method.
14. Petitot M, Boyer L, Minier C, Micard V (2010) Fortification of pasta with split pea and faba bean flours: pasta processing and quality evaluation. Food Res Int 43: 634-641.

15. AACC (2000) Approved Methods of the American Association of Cereal Chemists. Technology and Engineering 1-2: 1-1200.

16. Lee SC, Prosky L, DeVries JW (1992) Determination of total, soluble, and insoluble, dietary fiber in foods-enzymatic gravimetric method, MES-TRIS buffer: collaborative study. J AOAC Int 75: 395-416.

17. McCleary BV, Rossiter PC (2006) Dietary fibre and glycemic carbohydrates. In Gordon DT, Goda T (eds.) Dietary Fiber and its Energy Value.

18. Fish WW, Perkins-Veazie P, Collins JKA (2002) Quantitative assay fo lycopene that utilizes reduced volumes of organic solvents. J Food Comp Anal 15: 309-317.

19. Chillo S, Ranawana DV, Henry CJK (2011) Effect of two barley beta-glucan concentrates on in vitro glycaemic impact and cooking quality of spaghetti. LWT-Food Sci Tech 44: 940-948.

20. Navarro-González I, García-Valverde V, García-Alonso J, Periago MJ (2011) Chemical profile, functional and antioxidant properties of tomato peel fiber. Food Res Int 4: 1528-1535.

21. Cleary L, Brennan C (2006) The influence of a (1-3)(1-4)-- $\beta$-D-glucan rich fraction from barley on the physico-chemical properties and in vitro reducing sugars release of durum wheat pasta. Int J Food Sci Tech 41: 910-918.

22. Navarro MJ, Retamales J, Defilippi B (2001) Efecto del arreglo de racimo y aplicación de CPPU en la calidad de uva de mesa Sultanina tratada con dos fuentes de giberelinas. Agricultura Técnica 61: 15-21.

23. Švec I, Hrušková M, Vítová M, Sekerová H (2008) Colour evaluation of differen pasta samples. Czech J. Food Sci, 26: 421-427.

24. Cocci E, Sacchetti M, Vallicelli M, Angiolini A, Dalla RM (2008) Spaghett cooking by microwave oven: Cooking kinetics and product quality. J Food Eng 85: $537-546$

25. Laudadio V, Bastoni E, Introna M, Tufarellia V (2013) Production of low-fiber sunflower (Helianthus annuus $L$.) meal by micronization and air classification processes. CyTA-J Food 4: 398-403.

26. Yokoyama WH, Hudson CA, Knuckles BE, Chiu MCM, Sayre RN, et al. (1997) Effect of barley $\beta$-glucan in durum wheat pasta on human glycemic response. Cereal Chem 74: 293-296. 